\title{
CONTRIBUIÇÕES PARA COMPREENDER O QUE É DESENVOLVER O RACIOCÍNIO LÓGICO DOS ALUNOS: ESTUDO DO LIVRO ALICE NO PAÍS DAS MARAVILHAS
}

Denise VILELA ${ }^{1}$

Deizieli DORTA ${ }^{2}$

\begin{abstract}
RESUMO: O presente texto tem o intuito de explicitar princípios e regras da Lógica Clássica no contexto de uma obra clássica da literatura infantil, Alice no País das Maravilhas de Lewis Carroll. A obra analisada nos permite desenvolver uma compreensão crítica a respeito de objetivo freqüentes do ensino de matemática e orientações pedagógicas que frisam a importância de "desenvolver o raciocínio lógico", inclusive o PCN Matemática das séries iniciais. Trata-se de um estudo de filosofia da lógica, no âmbito da Educação Matemática. A ênfase aqui será nos princípios da lógica Clássica, sobretudo no Princípio da Identidade, já que a matemática se estrutura e desenvolve-se tendo como base nesta lógica. A obra de Carroll em análise possui tanto uma grande riqueza de apelos lógicos como também de coisas sem lógica e fantásticas que incita a criatividade e fantasia através das aventuras de Alice no universo maravilhoso da imaginação, do sonho e da infância. Essa abertura propicia abordar um conceito de infância e de Educação que preza pelo desenvolvimento integral da criança, no que diz respeito a aspectos intelectual e emocional.
\end{abstract}

PALAVRAS-CHAVE: Raciocínio lógico. Alice no País das Maravilhas. Lógica clássica. Educação matemática. PCN.

\section{Apresentação}

Uma orientação freqüente no ensino de matemática aponta para a importância de se desenvolver o raciocínio lógico do aluno. Neste artigo, o objetivo é apresentar uma compreensão a respeito deste tema, ou “o que é desenvolver o raciocínio lógico do aluno?

Alguns conceitos básicos de Lógica são explicitados e observados através de passagens do livro Alice no País das Maravilhas. A intenção é provocar uma reflexão a respeito dos princípios da Lógica Clássica, sobre os quais a matemática se desenvolve, a favor do desenvolvimento integral do aluno. Assim, este trabalho é precisamente de filosofia da lógica e Educação Matemática: desenvolvemos uma pesquisa através do estudo da lógica e da formulação de questões do ponto de vista da Educação Matemática, tais como: 'Que tipo de raciocínio a matemática desenvolve?’

\footnotetext{
${ }^{1}$ UFSCar - Universidade Federal de São Carlos. Departamento de Metodologia de Ensino. São Carlos - SP Brasil. 13565-905 - denisevilela@ufscar.br

${ }^{2}$ Professora de Educação Infantil. Rede Municipal de Ensino de Pirassununga. Pirassununga - SP - Brasil. 13.630-085 - deizi_dorta@yahoo.com.br
} 
O presente texto tem o intuito de explicitar princípios e regras da Lógica Clássica no contexto de uma obra clássica da literatura infantil, Alice no País das Maravilhas. A obra analisada nos permitir desenvolver uma compreensão crítica a respeito de objetivo freqüentes do ensino de matemática e orientações pedagógicas que frisam a importância de "desenvolver o raciocínio lógico”, em algumas vertentes indicando, inclusive, que deve ser estimulado desde primeira infância.

O Livro foi escrito por autor Charles L. Dogson por volta de 1950 que usou o pseudônimo Lewis Carroll para assinar a obra. O autor da obra e sempre teve grande interesse pela Lógica Matemática, atuando, inclusive, como professor de Matemática na Universidade de Oxford por vários anos.

A obra foi selecionada por ser rica em detalhes e tem reconhecida qualidade de penetrar tanto em aspectos lógicos como da fantasia. Lewis Carroll imprime na obra fortes características da lógica e uma reflexão sobre ela através de contradições lógicas, argumentos circulares, dificuldades do conceito de identidade, desenvolvimento de silogismos e falácias, e até mesmo do seu gosto pelos paradoxos e pelo nonsense, esbarrando nos limites da linguagem. Trata-se de utilizar conceitos da lógica e da anti-lógica para criar toda a fantasia encontrada nesse clássico:

Assim, um dos traços característicos da lógica de Charles Dodgson é o poder de forçar as leis da lógica, explorar os limites da linguagem simbólica, mostrar os limites das formulações, no fundo, revelar o nonsense que pode estar escondido sob a aparência da correção formal. (POMBO, 2009).

Todos os acontecimentos se passam durante um sonho da personagem principal. Bem diferente da vida entediada que tem, Alice passa por uma série de acontecimentos que quebram as regras do real e mergulham o leitor em um mundo de grande fantasia.

Na trama, Alice passa a adaptar seu comportamento a cada nova aventura que vive, tal como no encontro com a lagarta falante (e fumante) e com a rainha que quer cortar a cabeça de todos seus súditos. De fato, a história ocorre dentro de um universo infantil, em que a fantasia predomina e proporciona soltar a imaginação, liberar a criatividade e ainda auxilia a criar e/ou fortalecer o prazer pela leitura. Outra importante característica do livro é a presença de uma série de conceitos de Lógica que permeiam a história. O autor do clássico, Lewis Carrol, como matemático, lógico e romancista, atrela conceitos de lógica ao mundo de fantasia criado no sonho de Alice. 
Assim, o estudo e a análise desta obra são interessantes para o desenvolvimento de uma profunda compreensão da lógica na medida em que apresenta diversos conceitos desta ciência e, ao mesmo tempo, nega, contradiz, altera ou brinca com eles. Este recurso de alternar entre características que são da lógica e as que não são, possibilita uma compreensão mais ampla e profunda do que uma apresentação sistemática direta exclusivamente afirmativa do assunto. Para o Educador Matemático, especialmente, é de grande valor conhecer os limites e possibilidades do pensamento lógico dentro da linguagem humana, pois é inerente a prática do professor disciplinar o pensamento do aluno. Entendemos, levando em conta a noção de cultura escolar, que a escola não apenas transmiti conteúdos científicos como possui aspectos disciplinadores mais amplos, é um meio de aculturação, de imposição de regras e formas de pensamento (CHERVEL, 1990).

Tomamos como referência uma concepção de infância que valoriza o desenvolvimento integral da criança em seus aspectos sociais, culturais, intelectuais, psicológicos e físicos. A infância, deve ser considerada um período próprio da vida e não um período de preparação para o futuro:

Cada idade não está em função de outra idade. Cada idade tem, em si mesma, identidade própria, que exige uma educação própria, uma realização própria enquanto idade e não enquanto preparo para uma outra idade. [...] Cada fase da idade [...] tem que ser vivida na totalidade dela mesma e não ser submetida a futuras vivências [...] (ARROYO, 1995, p.19).

A escola, portanto, deve dar condições para todas as dimensões da pessoa no presente (ARROYO, 1995). Assim como entendemos que o desenvolvimento não deve ser impedido, podemos, com a mesma ênfase, afirmar que ele não deve ser forçado. Nessa medida, os compromissos, o desenvolvimento intelectual deve ser dosado com as necessidades de brincar, de fantasiar, de criar livremente. Especificamente, a matemática como disciplina escolar deve ser compreendida em sua base lógica, pelas suas relações com a linguagem natural. Nesta medida, no ensino infantil e fundamental deve-se valorizar o desenvolvimento integral do aluno, sendo importante trabalhar criticidade, criatividade, raciocínio lógico e capacidade de refletir.

Apresentamos em seguida uma discussão centrada em um dos três princípios da lógica, o Princípio da Identidade, ainda que a obra analisada, “Alice no País das Maravilhas” possibilite um campo interessante e potente para se entender o que é um o silogismo, uma inferência válida e as falácias. Essa discussão foi extraída de uma análise lógica - filosófica mais ampla da obra de Lewis Carroll, realizada por Dorta (2009), e tendo como referência central Shibles (1974), Machado e Cunha (2004). 


\section{Lógica: aspectos históricos e conceituais}

Consideramos que o termo lógica está sendo empregado aqui como Lógica formal, que trata dos conceitos, juízos e raciocínios, independentemente de seu conteúdo, tal como desenvolvido por Aristóteles (384 - 322 a.C.) e sistematizado e ampliado por Frege (18481925) denominado Lógica simbólica: ciência do desenvolvimento e representação de princípios lógicos mediante símbolos, a de constituir um cânone exato de dedução, baseado em idéias primitivas, postulados e regras de formação e transformação; também chamada lógica matemática.

A primeira sistematização da Lógica, chamada Clássica, foi realizada por Aristóteles que valoriza o raciocínio formalmente correto, que se baseia nos três princípios que regem as leis formais do pensamento lógico:

- $\quad$ Princípio da Identidade: cada coisa é igual a si mesmo, ou, em símbolos, $(\mathrm{A}=\mathrm{A})$;

- $\quad$ Principio da não Contradição: algo não pode ser e não ser ao mesmo tempo, ou, em símbolos, $\neg(\mathrm{A} \wedge \neg \mathrm{A})$;

- $\quad$ Princípio do terceiro Excluído: entre a afirmação e a negação não existe terceiro termo, ou, em símbolos, $(\mathrm{A} \vee \neg \mathrm{A})$.

A partir destes princípios, Aristóteles estruturou o silogismo, composto por duas proposições e uma conclusão, que seguindo as regras, conduzem a uma "inferência válida": de premissas verdadeiras chega-se sempre, a conclusões verdadeiras. Um argumento ou o silogismo é a junção das premissas com a conclusão. O argumento válido é aquele em que, supondo-se as premissas simultaneamente verdadeiras, decorre a verdade da conclusão. Sofisma (ou falácias) é o nome dado ao argumento não válido. Falácias informais são argumentos que parecem corretos, mas que quando realmente analisados não o são. Elas classificam-se como:

- $\quad$ De Ambigüidade: decorre dos vários sentidos associados a termos presentes nas premissas;

- $\quad$ Petição de Principio: tanto a premissa quanto a conclusão afirmam a mesma coisa.

- De irrelevâncias: argumento que ignora o conteúdo das premissas e ataca a pessoa argumentada. (MACHADO; CUNHA, 2004). 
O foco da presente abordagem se restringirá aos princípios mencionados acima, sobretudo no primeiro princípio, o de Identidade, que possui amplo potencial de reflexão na obra “Alice no País das Maravilhas”.

Os princípios e a relação da lógica com a argumentação permanecem quase que inalterados até o final do século XIX, quando Frege, na elaboração dos Fundamentos da Aritmética, emprega uma simbologia na sua estrutura lógica usada para demonstrar os princípios fundamentais da aritmética. O trabalho de Frege, o uso dos símbolos, são o marco inicial da Lógica Matemática.

A partir dos paradoxos, que surgem com os estudos de Frege, outras lógicas são desenvolvidas, as lógicas não clássicas, ou seja, “[...] a história duplamente milenar da lógica começou a mudar [...]. No momento ela versa sobre determinadas estruturas abstratas, que podemos denominar de sistemas lógicos, análogos, em espírito, às estruturas da álgebra ou de outros ramos da matemática.” (DA COSTA, 2002).

As chamadas Lógicas não - clássicas anteriormente citadas, podem basicamente ser divididas em duas espécies: as Complementares e as Heterodoxas.

As Complementares respeitam as regras e os princípios da Lógica Clássica, apenas inserindo alguns novos operadores de maneira a completar sua linguagem. Já as heterodoxas questionam e negam a Lógica Clássica, surgem com a intenção de substituí-la.

As lógicas heterodoxas nas quais não vale a lei reflexiva da identidade são
chamadas lógicas não-reflexivas. [...] Nas lógicas paracompletas não é
válido o princípio do terceiro excluído, ou seja, pode existir fórmula A tais
que nem A e nem a negação de A não são teoremas. O princípio da não-
contradição é derrogado nas lógicas relevantes e na maioria das lógicas
paraconsistentes. (D’OTTAVIANO; FEITOSA, 2003, p.22)

O interesse em mencionar os desenvolvimentos da lógica deve-se, na presente abordagem, a possibilidade de perceber a importância e as dimensões dos Princípios da lógica em todo seu desenvolvimento (e na sua relação específica com a matemática) pois é a alteração, eliminação ou substituição deles que promove desenvolvimentos significativos no campo da lógica. Serão consideradas a estrutura da argumentação e as definições do cálculo proposicional de primeira ordem da lógica clássica, numa linguagem intermediária entre a da matemática e a da argumentação. Esta opção deve-se a temática desenvolvida.

As relações entre Matemática e Lógica estão evidentes desde a sistematização da matemática da época realizada por Euclides, no século 3 a. C. Ele utilizou os princípios e 
regras da lógica aristotélica para organizar de forma axiomático-dedutiva os conteúdos matemáticos que já eram conhecidos na ocasião (VILELA, 1996).

Apresentamos em seguida uma discussão de um dos três princípios da lógica, o Princípio da Identidade.

\section{Discussão do princípio da identidade em Alice no País das Maravilhas}

O livro Alice no País das Maravilhas se inicia com a menina Alice entediada com um livro, que por não ter figuras ou diálogos, torna-se desinteressante. Dessa maneira, o autor expressa que a linguagem infantil inclui figuras, desenhos e conversas e não apenas palavras.

Sabemos que Alice vive suas aventuras enquanto sonha, ou seja, em estado inconsciente, e que todos os fatos acontecem numa diferente condição de espaço e tempo. Assim, o livro vai além do real, já que a personagem vive situações de sonho, e age entre sua vida normal e os absurdos do mundo onírico.

Logo no início aparece o primeiro traço nonsense, da obra, isto é, um coelho branco passa correndo e murmurando que está atrasado, enquanto confere as horas em um relógio de bolso. Eis um fato da qual não estamos habituados em nossa realidade, ou seja, trata-se de um acontecimento para nós, 'sem sentido’, se analisado do ponto de vista real, mas extremamente natural se lembrado após um sonho, um estado de inconsciência.

Alice, curiosa, segue o coelho e entra em uma toca que a leva a cair em uma espécie de túnel. Esse túnel pode ser considerado um rito de passagem, como se a menina estivesse saindo da vida real para entrar em um mundo de fantasia.

Ao cair e continuar seguindo o gato, Alice se vê numa sala cheia de portas trancadas e apenas uma que conseguira abrir, porém que tem apenas quarenta centímetros. Foi então que pela primeira vez, Alice alterou seu tamanho tomando o liquido de uma garrafa (com o rótulo: beba-me) que a fizera diminuir. Estaria aquela garrafa ali antes do desejo de Alice passar pela porta? Ou teria aparecido mediante sua vontade? Durante esse acontecimento Alice percebe que as regras que conhece não regem os acontecimentos naquele lugar. Mas e os princípios da lógica, permanecem? Especificamente: como fica, nesta situação, o princípio da identidade? A partir disso podemos pensar nas relações que temos com o mundo, e no quanto somos pequenos em relação a tantas coisas e grandes em relação a outras, o que nos leva a questionar a relação de nossas sensações com os princípios lógicos, em que se acredita que algo só poder ser o que é, ou seja, pode ser identificado aqui o Princípio da Identidade. 
E então Alice se questiona: "Posso terminar sumindo completamente como uma vela. E como é que eu seria depois disso?”3 Alice reflete nesse trecho a respeito das leis normais do mundo (leis aplicáveis fora do seu sonho), afinal se ela estava se tornando menor a cada momento por que não poderia ter um fim semelhante ao de uma chama de vela que desaparece após o mesmo processo? Reflete ainda, sobre sua “identidade essencial”. O que pode definir o que ela realmente é e quem ela realmente é?

Após diminuir, Alice se certificou de que a chave havia ficado em cima de uma mesa de vidro muito alta e briga consigo mesma como se existissem duas Alices agindo de maneiras diferentes. Uma apenas assistindo aos acontecimentos, outra os vivendo; uma fazendo loucuras e a outra repreendendo. Muitas vezes nos deparamos com uma espécie de conversa interior e nos perguntamos qual a nossa natureza? Qual a minha identidade? Qual é o meu verdadeiro? Quem sou eu? Desse modo autor explora esses questionamentos através dos pensamentos e das aventuras da menina.

Alice então encontrou um pedaço de bolo, devorando-o de uma só vez e esperou para ver o que aconteceria colocando a mão na cabeça para acompanhar o seu crescimento exterior, novamente, como se fossem duas pessoas. Uma crescendo e a outra analisando o crescimento. Afinal se Alice estava crescendo, tudo cresceria ao mesmo tempo e não seria possível analisar seu tamanho colocando a mão na cabeça.

No Capítulo 2: A lagoa de lágrimas, como se o autor ainda estivesse discutindo o principio da identidade, o bolo a fez esticar tanto que a preocupação de Alice foi “[...] e agora, quem é que vai calçar as meias e os sapatos em vocês, meus filhinhos?”. Ou seja, mediante o medo de cada novo acontecimento Alice passa a se comunicar com partes do corpo como se fossem outras pessoas, assim, a linguagem que o autor utiliza passa a não ser mais a convencional.

Após formar uma lagoa com suas lágrimas Alice novamente se encontra com o coelho que sempre apressado deixa cair uma luva e um leque e faz algumas conjecturas interessantes em relação ao o princípio da identidade: "Deus! Como tudo está tudo esquisito hoje. E ontem estava tudo tão normal. Será que eu mudei durante a noite? Deixe ver: eu era a mesma quando me levantei hoje de manhã? Estou quase jurando que me sentia um pouquinho diferente. Mas se não sou a mesma, então quem é que eu sou?”

Assim, podemos questionar: Será que somos os mesmos de um ano atrás? De um mês? Como serei daqui a dez anos? Quando passo por alguém na rua, a pessoa continua sendo a

\footnotetext{
${ }^{3}$ As citações de trechos do livro será destacada em negrito e não será mencionada o número da página pois várias traduções de “Alice...” foram utilizadas na análise realizada.
} 
mesma? Há alguma diferença nela? Percebemos então que o autor explora a construção do “Eu”, a verdadeira essência do ser humano mediante as situações variadas do cotidiano.

Alice interiormente questiona se teria se transformado em alguma de suas amigas. E em umas de suas falas transparece o princípio da identidade (A=A): “Não posso ser Mabel... além disso, ela é ela e eu sou eu”.

Alice tenta verificar que é a mesma e faz um auto-exame de seus conhecimentos. Assim, procura lembrar aquilo que aprendeu na escola, mas não consegue se lembrar de nada. Quando percebe isto, se compara a uma amiga que acredita ter pouco conhecimento e passa até a acreditar ser realmente ela. Mas será que uma pessoa é composta de suas idéias? E essas idéias não podem fazer parte da essência de outra pessoa?

Podemos observar mais uma vez o quanto o autor explora o nonsense, já que de dentro de uma sala trancada, surge uma praia em que o mar é formado pelas lágrimas que Alice havia derramado quando estava grande. É possível comparar ainda às histórias criadas pelas crianças, ou seja, trata-se de uma obra repleta de fantasia e ao mesmo tempo de trechos que nos permitem realizar várias reflexões.

A discussão a respeito da identidade, que nos ajuda a compreender limites e alcancer do princípio de mesmo nome, continua no capítulo 5: Conselhos de uma lagarta.

Ao encontrar a lagarta, esta a questiona: “Quem é você?” E Alice responde: “Nem eu mesmo sei, senhora, nesse momento... eu... enfim, sei quem era, quando me levantei hoje de manhã, mas acho que já me transformei várias vezes desde então.” (...) “ter tantos tamanhos diferentes num dia só é muito confuso.”. Esse trecho pode indicar as confusões que constituem cada idade. $\mathrm{O}$ autor expressa todas elas sendo vividas simultaneamente por uma garota que supostamente cresce e diminui constantemente, ou seja, mostrando o quanto se torna difícil quando ela não sabe se é grande ou pequena. Podemos observar em outros trechos que quando Alice está grande, se sente mais velha. E assim, as confusões de idade e tamanho interferem na formação de sua identidade, fazendo-a extremamente confusa. Outro fator interessante se refere às sensações de Alice, que também sentimos constantemente. Quantas vezes nos sentimos pequenos e inferiores? E em quantas situações nossa auto-estima se eleva? Isso acontece várias vezes e inclusive no mesmo dia. Assim, percebemos que Alice sente grandes dificuldades já que, não se reconhecendo oscila em seus próprios sentimentos.

\section{Considerações Finais}


Destacamos inicialmente o potencial do livro Alice no País das Maravilhas para compreender o que é no desenvolvimento do raciocínio lógico proposto para os alunos de Ensino Fundamental I, considerando os conceitos de lógica que podem ser estudados no contexto da obra. A compreensão dos conceitos lógicos fica mais clara através dos personagens que conviveram com Alice e das aventuras que a menina vive nesse seu mundo de sonhos e fantasias.

Utilizando-se de um roteiro supostamente infantil, Carroll permeia a história de Alice com temas da lógica os entre os quais alguns foram explorados neste estudo: os três princípios básicos da Lógica Clássica, o Princípio da Identidade, Princípio da não Contradição e Princípio do terceiro excluído.

No decorrer do trabalho percebemos que o objetivo de desenvolver o raciocínio lógico da criança deve ser considerado no contexto do desenvolvimento integral da criança, ou seja, deve ser considerado tanto quanto o desenvolvimento de aspectos sociais, culturais, psicológicos, físicos e emocionais. A criança deve ser considerada como um ser completo e não mais, como já se acreditou, como um adulto pequeno, um adulto em desenvolvimento (ARROYO, 1995)

Assim, consideramos o potencial deste trabalho para professores ou futuros professores, tanto de matemática quanto das séries iniciais do Ensino Fundamental.

Concluímos, portanto, que este é um trabalho que permite uma série de reflexões interessantes sobre o pensamento lógico, para docentes, afim de que o trabalho educacional com o Raciocínio Lógico seja consciente e desenvolvido conjuntamente à criatividade e à imaginação da criança.

\title{
UNDERSTANDING WHAT MEANS TO DEVELOP STUDENT'S LOGICAL THOUGHT: A STUDY OF THE BOOK “ALICE IN WONDERLAND”
}

\begin{abstract}
This article aims to present principles and rules of Classical Logic within a masterpiece of infant literature "Alice in Wonderland", by Lewis Carrol. The book provides a critical comprehension related to the usual objectives in Mathematical teaching and pedagogical orientations to outline the importance to "develop logical thinking”, including Mathematic's PCN for. It is a study in the field of philosophy of logic within Mathematical Education. The emphasis lies on the principles of classical logic, mainly on Identity Principle, since mathematics structures and develops itself based on this logic. Carrol's book pursuits many logical topics and nonsense situations that stimulate creativiness and phantasy through Alice's adventures in the realm of wonderful imagination universe, of dream and childhood.
\end{abstract}


This departure allows to approach a concept of childhood and education that cares for a whole child's development, relating to emotional and intellectual aspects.

KEYWORDS: Logical thought. Alice in Wonderland. Classical logic. Mathematical education. PCN.

\section{REFERÊNCIAS}

ARROYO, M. G. O significado da infância. Revista Criança: do professor de educação infantil, Brasília, n. 28, p.17-21, 1995.

CHERVEL, A. História das disciplinas escolares: reflexões sobre um campo de pesquisa. Teoria \& Educação, Porto Alegre, v.2, p.177-229, 1990.

DORTA, D. A. Um estudo sobre a lógica matemática no livro "Alice no País das Maravilhas”. 2009. Trabalho de Conclusão de Curso (Licenciatura Plena em Matemática) Universidade Federal de São Carlos, São Carlos, 2009.

D’OTTAVIANO, Í. M. L.; FEITOSA, H. de A. Sobre a história da lógica, a lógica clássica e o surgimento das lógicas não-clássicas. Disponível em:

$<\mathrm{ftp}$ ://ftp.cle.unicamp.br/pub/arquivos/educacional/ArtGT.pdf>. Acesso em: 15 jun. 2009.

MACHADO, N. J.; CUNHA, M. O. da. Lógica e senso comum: frases, argumentos, verdade, validade. [S.l.], 2004. Apostila.

POMBO, O. Quem foi Lewis Carroll? Disponível em:

$<$ http://www.educ.fc.ul.pt/docentes/opombo/seminario/alice/lewis_carroll.htm>. Acesso em:

20 abr. 2009.

SHIBLES, W. Wittgenstein, linguagem e filosofia. São Paulo: Cultrix, 1974.

VILELA, D. S. Análise das críticas de Frege a Cantor: a noção de número e o emprego da abstração nas definições. 1996. 124f. Dissertação (Mestrado em Filosofia) - Instituto de Filosofia e Ciências Humanas, Universidade Estadual de Campinas, Campinas, 1996.

\section{BIBLIOGRAFIA CONSULTADA}

ABAR, C. Noções de lógica matemática. Disponível em:

<http://www.pucsp.br/ logica/Proposicional.htm>. Acesso em: 04 jun. 2009. 
ALICE no País das Maravilhas [Alice's Adventures in Wonderland]. 2007. Disponível em: $<$ http://fenrisulfr.multiply.com/reviews/item/9.>. Acesso em: 16 jun. 2009.

BRASIL. Parecer CNE/CES 1.302/2001. Diretrizes curriculares para cursos de matemática, bacharelado ou literatura. Diário Oficial da União, Brasília, 05 mar. 2002. Seção 1, p.15.

CARROL, L. Aventuras de Alice no País das Maravilhas: através do espelho e o que Alice encontrou lá. São Paulo: Summus Editorial, 1980.

CUNHA, M. O. da. Lógica e senso comum: o diálogo precisão / ambigüidade. 2004. Disponível em: <http://www.educarede.org.br/educa/img_conteudo/File/CV_132//2004-0827-Logica_e_senso_comum_-_o_dialogo_precisao-ambiguidade.doc $>$. Acesso em: 20 jun. 2009.

MORETTI, A. O gato de Alice. Disponível em:

$<$ http://www.facasper.com.br/cultura/site/livros.php?tabela=\&id=62>. Acesso em: 08 abr. 2009.

PINTO, G. F. S. Análise filosófica da obra Alice no país das maravilhas. Disponível em: $<$ http://www.ump.edu.br/midialogos/ed_02/ensaios/Analise\%20Filosofica.pdf $>$. Acesso em: 16 jun. 2009.

SMOLE, K. S. et al. Era uma vez na matemática: uma conexão com a literatura infantil. São Paulo: Caem: USP, 2004.

SMOLE, K. S.; DINIZ, M. I. Ler, escrever e resolver problemas: habilidades básicas para aprender matemática. Porto Alegre: Artmed, 2001. 